\title{
Formulation and Evaluation of Asenapine Maleate Loaded Niosomes for the Treatment of Schizophrenia
}

\author{
Rudra Pratap Singh ${ }^{1, \star}$, Ramakant M Narke ${ }^{2}$, Pooja V Jadhav ${ }^{2}$ \\ ${ }^{1}$ Department of Pharmaceutics, Columbia Institute of Pharmacy, Raipur, Chhattisgarh, INDIA. \\ ${ }^{2}$ Sinhgad College of Pharmacy, Vadgaon (BK) Pune, INDIA.
}

\begin{abstract}
Background: Niosomes are the non-ionic surface-active agent primarily based vesicles. The Key obstacle of Asenapine maleate have oral bioavailability $(<2 \%)$ and extensive first pass effect. Objectives: The objective key of the existing work was to formulate Asenapine maleate loaded niosomes using quality by design and rectify it with some evaluation parameters to increase bioavailability, to lead better therapeutic effect and to minimize the side effects. Methods: Formulation of niosomes was done by three methods organic solvent injection method. Factorial design $\left(3^{2}\right)$ experiments are significantly used to screen and to observe the effect of independent variables cholesterol and span $60\left(X_{1}, X_{2}\right)$ on dependent variables particle size and entrapment efficiency $\left(Y_{1}, Y_{2}\right)$. Results: The results revealed optimized formulation ASP-niosome A2 amongst other formulations which was found lowest particle size $84 \pm 5 \mathrm{~nm}$ and highest \% EE $70 \pm$ $2.0 \%$. In-vitro drug release of optimized noisome was found $68 \pm 1.20 \%$ at the end of $8 \mathrm{hr}$ and zeta potential was $-17.53 \mathrm{mV}$ which stabilized the niosomal suspension. Characterization by SEM not only indicated the spherical shape of the niosomes but also confirmed the formation of vesicle. Locomotor activity was found to be significant in in-vivo pharmacodynamic study. Pharmacokinetic study carried out and it showed $\mathrm{C}_{\max }$ and $t_{1 / 2}$ of $16.12 \mathrm{ng} / \mathrm{mL}$ and $37.18 \mathrm{hr}$ which is better than reported parameters for drug. Conclusion: Thus, concluded that Asenapine maleate loaded niosomes having effective anti-psychotic activity with increased bioavailability could be prepared successfully by organic solvent injection method using span 60 and cholesterol.
\end{abstract}

Key words: IJPER, Citation profile, Scientometrics, Pharmaceutics, Journal evaluation.

\section{INTRODUCTION}

Schizophrenia is a chronic and severe brain disorder that affects the behavior, thinks and imagination ways of a person. Positive, negative and cognitive symptoms are characterized for this disorder in which, delusion, hallucination, disorganized speech and behavior are more important and considerable. ${ }^{1}$ Many antipsychotic medications are available in the market but no any single medicament is efficient for schizophrenia patients. The other available treatment options are also not effective in treating. So, these all unsatisfied responses increased the patient noncompliance. ${ }^{2-4}$ Niosomes are non-ionic surface active agents based vesicles. It is formed closed bilayer a structure by the self-assembly of non-ionic amphipiles in aqueous media with the help of physical agitation or by heat energy where medicament is encapsulated in a vesicle. ${ }^{5,6}$ Niosomal structure has hydrophobic parts as well as hydrophilic parts.

Asenapine maleate (ASP) is an atypical antipsychotic multi-receptor neuroleptic drug which shows strong antagonism effects on serotonin, dopamine, noradrenaline and histamine receptors. Sedation in patients is associated with asenapine's antagonist activity at histamine receptors. Their lower incidences of extrapyramidal effects are associated with the up regulation of D1 receptors. This up regulation occurs due
Submission Date: 21-10-2019; Revision Date: 21-01-2020; Accepted Date: 26-02-2020

DOI: 10.5530/ijper.54.2s.69 Correspondence: Dr. Rudra Pratap Singh Department of Pharmaceutics, Columbia Institute of Pharmacy, Raipur - 493111, INDIA.

Phone: +91-7697553227

E-mail: rudra.p.s007@gmail. com

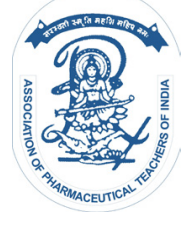

www.ijper.org 
to asenapine's dose dependent effects on glutamate transmission in the brain. The sublingual formulation and evaluation of ASP has been studied and already reported that showed an ideal bioavailability of $35 \%$, provided that during its absorption there is no interaction with liquids or foods, mainly fats, over a variable period of time (from $10 \mathrm{~min}$ to $4 \mathrm{hr}$ ) after it is administered. Asenapine maleate shows a nonlinear type of pharmacokinetics in relation to the dose. The double dose of ASP (5-10 mg twice daily) results in 1.7-fold increase in maximum concentration and exposure. ASP may antagonize the targeted disease in the patients. ${ }^{6-9}$ Niosomes of Asenapine maleate could be a very useful as a drug delivery system for the treatment of brain disorders (Figure 1) or others as well as for the use of other hydrophobic and hydrophilic drugs.

In pharmaceutical industries, factorial design experiments are significantly used to screen and to confirm the product design space. Risk assessment of the manufacturing process is a crucial action in product manufacturing and development, particularly as a backing tool in Quality by Design (QbD). ${ }^{10-12}$ In present research work, niosomes have formulated with different process and formulation variables.

\section{MATERIALS AND METHODS Materials}

Asenapine maleate (ASP) was gifted by Lupin Research Park, Pune, India. Cholesterol and Span 60 were purchased from Loba Chemie Pvt. Ltd Mumbai, India. HPLC grade of Chloroform and Acetonitrile and other chemicals were purchased from Loba Chemie Pvt. Ltd., Mumbai, India.

\section{Experimental Animals}

To accomplish the objectives of this experiment, Sprague-Dawley rats (200-250 gm) were procured from National Institute of Biosciences, Pune. The protocol and procedure for this study was approved by Institutional Animal Ethics Committee (SCOP/ IAEC/2013-14/179).

\section{Methods}

\section{Solubility studies}

The solubility of ASP was carried out in the Phosphate buffer saline (PBS pH 7.4) and in other organic solvents. The specific weighed amount of $1 \mathrm{mg}$ of ASP was dissolved in $5 \mathrm{~mL}$ of PBS and in other organic solvents and ultra sonicated for $15 \mathrm{~min}$ to get a clear solution, then it centrifuged for $10 \mathrm{~min}$ at $8000 \mathrm{rpm}$. After the centrifugation, the supernatant liquid was collected by filtration and further, the concentration of drug was assessed by using UV spectrophotometer (Shimadzu, UV-1800, Japan) at $269 \mathrm{~nm}$ for PBS and for other organic solvents at different and specific absorbance values. ${ }^{4,13}$

\section{Fourier Transform Infrared (FT-IR) spectroscopy studies}

The FT-IR spectroscopy was employed to characterize the possible interaction between ASP with cholesterol and ASP with span 60 in the solid state. It was recorded using FT-IR spectrophotometer (Perkin Elmer, Spectrum BX, USA) by using $\mathrm{KBr}$ pellet technique in scanning frequency range of $4000-400 \mathrm{~cm}^{-1}$ with a resolution of $40 \mathrm{~cm}^{-1} .^{14-16}$

\section{Differential Scanning Calorimetry (DSC) studies}

Differential scanning calorimetry (DSC, Stare System, Mettler Toledo) was used to assessed the thermal analysis interactions between ASP with cholesterol and ASP with span 60. Weighed amount of $2 \mathrm{mg}$ of ASP alone and with mixtures were transferred into instrument. Then, it was scanned rate of $10^{\circ} \mathrm{C} / \mathrm{min}$, over a temperature range of $30-300^{\circ} \mathrm{C}$ in the environment of liquid nitrogen (Flow rate $60 \mathrm{~mL} / \mathrm{min}$ ). ${ }^{13,15,16}$

\section{Preliminary studies for preparation of niosomes Hand Shaking (Rotary Evaporator) Method}

The specific weighed amount of $5 \mathrm{mg}$ of span 60 and cholesterol were mixed together in round bottom flask. Then mixture was dissolved in chloroform, later on organic phase was evaporated using rotary evaporator instrument under low vacuum. The precipitate thin film was hydrated by using aqueous phase of different weighted amount of ASP such as $5 \mathrm{mg}, 7.5 \mathrm{mg}$ and 10 mg (PBS + ASP) on water bath. Later on this niosomal suspension formed was shaken and kept for maturation at $4^{\circ} \mathrm{C}$ freezer. ${ }^{17}$

\section{Sonication Method}

The excess amount of $5 \mathrm{mg}, 7 \mathrm{mg}$ and $10 \mathrm{mg}$ of ASP, 5 $\mathrm{mg}$ of span 60 and $5 \mathrm{mg}$ of cholesterol were dissolved separately in phosphate buffer saline $\mathrm{pH} 7.4$ and chloroform. The ASP solution was added in the mixture solution of chloroform and then sonicated at $60^{\circ} \mathrm{C}$ for 3 minutes using a sonicator with a titanium probe. ${ }^{18}$

\section{Organic Solvent Injection Method}

Initially $5 \mathrm{mg}$ of span 60 was mixed with $5 \mathrm{mg}$ of cholesterol and later on was dissolved in chloroform. Then mixture was introduced into the solution of phosphate buffer saline (PBS) $\mathrm{pH} 7.4$ containing $5 \mathrm{mg}$, $7.5 \mathrm{mg}$ and $10 \mathrm{mg}$ of ASP using 21 gauge needle under 
constant magnetic stirring at $60^{\circ} \mathrm{C}$ temperature. Thus the chloroform as an organic solvent was vaporized to form single layered niosomes. ${ }^{19}$

Preparation and evaluation of preliminary trial batches for selection of method of preparation and concentration range of drug (ASP)

Various trial batches were prepared accordingly for all 3 methods as mentioned in Table 1 and as per the procedure mentioned above. The selection of method was based on PS (nm) and \% EE. Cholesterol was used as vesicle stabilizing agent. From the less PS and \%EE, span 60 was selected as a surfactant and organic solvent injection was selected as a method that shown as in Table 2.

\section{Preparation of Niosomes}

ASP-Niosomes were prepared by organic solvent injection method. The opaque niosome suspension was formed spontaneouslyin theabovementioned conditions. Niosomes were separated by ultracentrifugation $(\mathrm{M} / \mathrm{S}$ Remi instruments Pvt. Ltd., Mumbai (REMI C-24 BL) at $18,000 \mathrm{rpm}$ for $60 \mathrm{~min}$, at $2-8^{\circ} \mathrm{C}$.

\section{Factorial Design of Experiment}

In this study, the factorial design $3^{2}$ was used, where two factors and three levels experimental was performed in all combinations. The amount of Cholesterol (X1) and the Span 60 (X2) were chosen as independent variables, while particle size (PS) and entrapment efficiency (EE) were selected as a response / dependent variables. The factorial design matrix for all batches A1-A9 was shown in Table 3. The resultant data were incorporated into Design Expert V-8 registered software (Stat Ease Inc. Minneapolis USA) and statistically analyzed using polynomial regression equations, ANOVA and 3D response surface methodology. ${ }^{15,20-22}$

\section{Characterization of Niosomes}

\section{Particle size analysis}

The average diameter of ASP-niosomes was determined by Photon Cross-correlation Spectroscopy (PCCS) using Zeta-Sizer Nano-ZS90, Malvern, UK at room temperature. $5 \mathrm{mg}$ of ASP-niosomes was dissolved in distilled water and further it was transferred into sample dispersion unit with continuous stirring to minimize the aggregation. ${ }^{15,16,23}$

\section{Entrapment efficiency}

To obtain the percentage drug entrapment efficiency of ASP-niosomes, the centrifugation method was applied. In this method, firstly the niosomes was centrifuged at $9000 \mathrm{rpm}$ for $15 \mathrm{~min}$ then, the supernatant was analyzed by UV visible spectrophotometer. The percentage drug entrapment efficiency was determined by following equation. ${ }^{13,15,16}$

$\% \mathrm{EE}=\frac{\text { Mass of drug in niosomes }}{\text { Mass of drug used in preparation }} \times 100$

\section{In vitro drug release study}

In this method, firstly sample solution of $5 \mathrm{~mL}$ of ASP-niosome was kept in a dialysis bag (cellophane membrane, molecular weight cut off 10,000-12,000, Hi-Media, India). Further, it was dipped into the dissolution beaker containing the $900 \mathrm{~mL}$ of phosphate buffer ( $\mathrm{pH}$ 7.4) dissolution medium. The complete apparatus was performed at $50 \mathrm{rpm}$ and $37 \pm 0.5^{\circ} \mathrm{C}$ temperature. As per the required time being, the aliquots were withdrawn from the release medium and replaced with the same up to $8 \mathrm{~h}$. The all sample was assayed in UV spectrophotometrically at $269 \mathrm{~nm} \cdot{ }^{12-14}$ Further, the kinetic modelling of Dissolution data was subjected to PCP-Disso-v3 software to find out the release pattern. ${ }^{15-16}$

\section{Surface morphology}

To carry out the surface morphology, Scanning Electron Microscopy (SEM) using JEOL JSM-6360 (Japan) was utilized. In this, a drop of suspension of optimize ASPniosome was placed on a slide slip before it was fixed, dehydrated and freeze dried then it was scanned at different magnifications. ${ }^{15,16,23}$

\section{Validation of optimized preparations/check point analysis}

Numerical optimization was performed in order to predict a niosome preparation with particle size less than the $100 \mathrm{~nm}$ and maximal \% yield from the model generated. By numerical optimization method two check point batches ( $\mathrm{C} 1$ and $\mathrm{C} 2$ ) were prepared to validate the model. ${ }^{24-26}$ The coded values of independent variables of two checkpoint batches and their predicated responses are given in result and discussion part, Table 4.

\section{In-vivo Studies}

\section{Pharmacodynamics study}

Spragur-Dawley rats (200-250 gm) were divided into the four groups $(n=6)$

Group I: Normal (control) group

Group II: Psychosis induced (Ketamine) group

Group III: ASP-API group

Group IV: ASP-niosome A2 group

To induce the psychosis activity and behavioral response of all groups of animals, $30 \mathrm{mg} / \mathrm{kg}$ ketamine injected i.p. daily for five consecutive days. On sixth day, before 
30 min of assessment of animals activity, control group (Group I) was treated with saline and other groups of animals of III and IV were treated orally with $0.3 \mathrm{mg} / \mathrm{kg}$ of asenapine maleate solution (API) and ASP-niosome $\mathrm{A} 2$ and the locomotor activity was assessed for $5 \mathrm{~min}$ in an open field chamber. ${ }^{4,27-31}$

\section{Pharmacokinetic study}

For the assessment of pharmacokinetic parameters, group of animals of I, III and IV was selected with administered p.o. dose of saline and $0.3 \mathrm{mg} / \mathrm{kg}$ of asenapine maleate solution (API), ASP-niosome A2 to respective groups. Blood samples were collected by retro orbital route at different time intervals of $1,2,3$, 4, 5, 6, 7 and $8 \mathrm{hr}$ in heparinized tube for a single day. To separate the plasma, the collected blood samples were centrifuged at $8000 \mathrm{rpm}$ for $10 \mathrm{~min}$ and stored at $-20^{\circ} \mathrm{C}$. Then, it was assayed by HPLC analysis under Acetonitrile: potassium dihydrogen phosphate buffer $\mathrm{pH} 3.2(60: 40 \mathrm{v} / \mathrm{v})$ and $\mathrm{C}_{18}$ column chromatographic conditions.

\section{Statistics and Calculations}

Pharmacokinetic parameters were computed with the non-compartmental model strategy. The most extreme plasma drug concentration $\left(\mathrm{C}_{\max }\right)$ and the time required $\left(\mathrm{T}_{\max }\right)$ by the drug to achieve $\mathrm{C}_{\max }$ were taken from the concentration - time curve. The area under the plasma drug concentration-time curve to the last quantifiable concentration $\left(\mathrm{AUC}_{0-\mathrm{t}}\right.$ ) was figured using the Trapezoidal rule. The terminal phase was dictated by outwardly inspecting the log-transformed concentration-time curve. The area under the plasma concentration-time curve to infinity $\left(\mathrm{AUC}_{0-\infty}\right)$ was evaluated by joining AUC0-t with $\mathrm{AUC}_{\mathrm{t}-\infty}$, where $\mathrm{AUC}_{\mathrm{t}-\infty}$ represents the residual area of the drug from time to infinity and was computed by isolating the last quantifiable plasma drug concentration value by the elimination rate constant (KE). The time required for the drug to diminish its concentration to half $\left(\mathrm{t}_{1 / 2}\right)$ was figured as $0.693 / \mathrm{K}_{\mathrm{E}}$.

\section{Pharmacodynamics Study}

The psychosis activity and behavioral response of all groups of animals were performed in an open field chamber.

\section{RESULTS AND DISCUSSION}

\section{Solubility studies}

The solubility of ASP in pH 7.4 (Phosphate Buffer Saline) and in other organic solvents were determined. In aqueous solution, ASP was showing insoluble, where in chloroform, DCM and methanol, it was found slightly-sparingly soluble. ASP was found to be 2.408 $\pm 0.7 \mathrm{mg} / \mathrm{mL}$ in PBS pH 7.4 $(n=3)$ and the correlation coefficient $R^{2}$ value was $0.997 \pm 00.13$.

\section{FT-IR spectroscopy studies}

As depicted in Figure 2 and Figure 3, the FTIR spectra of ASP revealed high intensity broad bands at approximately $650 \mathrm{~cm}^{-1}\left(\mathrm{C}-\mathrm{Cl}\right.$ stretching), $1093 \mathrm{~cm}^{-1}$ (-O- of Ether), 1485 and $1618 \mathrm{~cm}^{-1}$ (C=C aromatic), $1706 \mathrm{~cm}^{-1}$ ( $\mathrm{C}=\mathrm{O}$ of Acid), $2288 \mathrm{~cm}^{-1}$ ( $\mathrm{C}=\mathrm{N}$ stretching), 2960 and $3038 \mathrm{~cm}^{-1}$ (C-H alkane) and $3417 \mathrm{~cm}^{-1}$ (H-C= aromatic stretching). These peaks have also been observed in a physical mixture of ASP with span 60 and ASP with cholesterol. Thus, the excipients and ASP didn't interact with each other and confirm the formation of a spherical vesicle.

\section{Differential scanning calorimetry studies}

Differential Scanning Calorimetry studies (Figure 4) indicated a sharp endothermic peak at $146^{\circ} \mathrm{C}$ corresponding to melting of pure ASP. The peaks broadening as well as change in relative intensities were observed due to dilution of drug in physical mixtures of ASP with span 60 and ASP with cholesterol. It is concluded the confirmation of complex formation.

\section{Preliminary studies for preparation and evaluation of niosomes}

From the less particle size and higher entrapment efficiency, span 60 was selected as a surfactant and organic solvent injection was selected as a method that shown as above in Table 2.

\section{Factorial design and statistical analysis}

A $3^{2}$ full factorial design was constructed to study the effect of the amount of independent variables X1, X2 (cholesterol and span 60) on the dependent variables Y1, Y2 (particle size and entrapment efficiency) of ASPniosomes. A statistical model incorporating interactive and polynomial terms was utilized to evaluate the responses.

$\mathrm{Y}=\beta 0+\beta 1 \mathrm{X} 1+\beta 2 \mathrm{X} 2+\beta 12 \mathrm{X} 1 \mathrm{X} 2+\beta 11 \mathrm{X} 12+\beta 22 \mathrm{X} 22-----$ (2)

\section{Characterization of niosomes}

\section{Particle size}

The average diameter of the prepared ASP-niosomes is summarized in Table 5 and Table 6 . The particle size of the prepared ASP-niosomes was found in the range of $84 \pm 5 \mathrm{~nm}$ to $296 \pm 5 \mathrm{~nm}$. ASP-niosome A2 shows the lowest particle size $84 \pm 5 \mathrm{~nm}$ and A1 shows highest particle size $296 \pm 4 \mathrm{~nm}$ that shown in Figure 5 .

With increasing in the concentration of cholesterol and span 60 were found to influence or increase the particle 


\begin{tabular}{|c|c|c|c|c|c|c|}
\hline \multirow[t]{2}{*}{ Run } & \multirow[t]{2}{*}{ Surfactant } & \multirow{2}{*}{$\begin{array}{c}\text { Cholesterol: Span } \\
\text { 60:Drug }\end{array}$} & \multirow[t]{2}{*}{ Method } & \multicolumn{3}{|c|}{ Weight (mg) } \\
\hline & & & & Cholesterol & Span 60 & Drug \\
\hline $\mathrm{T}_{1}$ & Span 60 & 1:1:1 & Organic Solvent Injection & 5 & 5 & 5 \\
\hline $\mathrm{T}_{2}$ & Span 60 & $1: 1: 1.5$ & Organic Solvent Injection & 5 & 5 & 7.5 \\
\hline $\mathrm{T}_{3}$ & Span 60 & $1: 1: 2$ & Organic Solvent Injection & 5 & 5 & 10 \\
\hline $\mathrm{T}_{4}$ & Span 60 & 1:1:1 & Sonication & 5 & 5 & 5 \\
\hline $\mathrm{T}_{5}$ & Span 60 & $1: 1: 1.5$ & Sonication & 5 & 5 & 7.5 \\
\hline $\mathrm{T}_{6}$ & Span 60 & $1: 1: 2$ & Sonication & 5 & 5 & 10 \\
\hline $\mathrm{T}_{7}$ & Span 60 & 1:1:1 & Hand shaking & 5 & 5 & 5 \\
\hline $\mathrm{T}_{8}$ & Span 60 & $1: 1: 1.5$ & Hand shaking & 5 & 5 & 7.5 \\
\hline $\mathrm{T}_{9}$ & Span 60 & $1: 1: 2$ & Hand shaking & 5 & 5 & 10 \\
\hline
\end{tabular}

\section{Table 2: Evaluation of Preliminary Trial Batches for Selection of Method of Preparation.}

\begin{tabular}{|c|c|c|c|c|c|c|c|c|}
\hline \multicolumn{3}{|c|}{ Organic solvent injection method } & \multicolumn{3}{|c|}{ Sonication method } & \multicolumn{3}{|c|}{ Hand shaking method } \\
\hline $\begin{array}{l}\text { Formulation } \\
\text { code }\end{array}$ & $\begin{array}{l}\text { PS } \\
(\mathrm{nm})\end{array}$ & $\%$ EE & $\begin{array}{l}\text { Formulation } \\
\text { code }\end{array}$ & $\begin{array}{l}\text { PS } \\
(n m)\end{array}$ & $\% \mathrm{EE}$ & $\begin{array}{c}\text { Formulation } \\
\text { code }\end{array}$ & $\begin{array}{l}\text { PS } \\
(\mathrm{nm})\end{array}$ & $\%$ EE \\
\hline $\begin{array}{c}\mathrm{T} 1 \\
(\mathrm{span60)}\end{array}$ & 506 & 54 & $\begin{array}{c}\mathrm{T} 4 \\
(\mathrm{span60)}\end{array}$ & 758 & 18 & $\begin{array}{c}\mathrm{T7} \\
\text { (span60) }\end{array}$ & 7154 & 33 \\
\hline $\begin{array}{c}\mathrm{T} 2 \\
(\text { span60) }\end{array}$ & 884 & 67 & $\begin{array}{c}\text { T5 } \\
(\text { span60) }\end{array}$ & 1118 & 27 & $\begin{array}{c}\text { T8 } \\
\text { (span60) }\end{array}$ & 6908 & 44 \\
\hline $\begin{array}{c}\text { T3 } \\
(\text { span60) }\end{array}$ & 1045 & 84 & $\begin{array}{c}\text { T6 } \\
\text { (span60) }\end{array}$ & 2158 & 55 & $\begin{array}{c}\text { T9 } \\
\text { (span60) }\end{array}$ & 8700 & 52 \\
\hline
\end{tabular}

\begin{tabular}{|c|c|c|c|c|c|c|c|}
\hline \multirow[t]{2}{*}{ Run } & \multicolumn{2}{|c|}{ Coded Values } & \multicolumn{2}{|c|}{$\begin{array}{l}\text { Actual Values (mg/ } \\
\text { mL) }\end{array}$} & \multirow[t]{2}{*}{$\begin{array}{l}\text { Asenapine maleate } \\
\text { (mg) }\end{array}$} & \multirow[t]{2}{*}{ Chloroform (mL) } & \multirow[t]{2}{*}{$\begin{array}{c}\text { Phosphate buffer } \\
\text { pH } 7.4(\mathrm{~mL})\end{array}$} \\
\hline & $x_{1}$ & $x_{2}$ & $x_{1}$ & $x_{2}$ & & & \\
\hline$A_{1}$ & -1 & -1 & 5 & 10 & 5 & 6 & 30 \\
\hline $\mathrm{A}_{2}$ & 0 & -1 & 10 & 10 & 5 & 6 & 30 \\
\hline $\mathrm{A}_{3}$ & +1 & -1 & 15 & 10 & 5 & 6 & 30 \\
\hline $\mathrm{A}_{4}$ & -1 & 0 & 5 & 15 & 5 & 6 & 30 \\
\hline$A_{5}$ & 0 & 0 & 10 & 15 & 5 & 6 & 30 \\
\hline$A_{6}$ & +1 & 0 & 15 & 15 & 5 & 6 & 30 \\
\hline $\mathrm{A}_{7}$ & -1 & +1 & 5 & 20 & 5 & 6 & 30 \\
\hline$A_{8}$ & 0 & +1 & 10 & 20 & 5 & 6 & 30 \\
\hline$A_{9}$ & +1 & +1 & 15 & 20 & 5 & 6 & 30 \\
\hline
\end{tabular}

size of the prepared ASP-niosomes. The polynomial equation for particle size was found as shown below

$\mathrm{Y} 1(\mathrm{PS})=+106.56-16.33 \times 1-12.00 \mathrm{X} 2+71.75 \times 1 \times 2+111.67 \mathrm{X} 12-$ $22.33 \times 22-----(3)$

The results of multiple linear regression analysis showed that both the coefficients $\beta 1$ and $\beta 2$ bear a positive sign. Therefore, increasing the concentration of either cholesterol or span 60 is expected to increase the particle size. The result of analysis of Variance for Y1 (particle size) was shown in Table 6, that indicates the quadratic model was found an adequate model. The three-dimensional response surface plot was shown in Figure 6 and Contour plot Figure 7 indicates the effect of cholesterol and span 60 on the particle size of niosomes.

\section{Entrapment efficiency}

The $\%$ EE of ASP-niosomes was found in the range of $53 \pm 4.5-89 \pm 0.5 \%$. It was influenced by the amount of cholesterol and span 60 are given in Table 5 and Table 7 , depict the results of entrapment efficiency obtained 


\begin{tabular}{|c|c|c|c|c|c|c|c|}
\hline \multirow{2}{*}{$\begin{array}{l}\text { Check } \\
\text { point } \\
\text { batches }\end{array}$} & \multicolumn{2}{|c|}{$\begin{array}{l}\text { Independent } \\
\text { Variables }\end{array}$} & \multirow[t]{2}{*}{$\begin{array}{l}\text { Response } \\
\text { variables }\end{array}$} & \multirow[t]{2}{*}{$\begin{array}{l}\text { Predicted } \\
\text { value }\end{array}$} & \multirow[t]{2}{*}{$\begin{array}{l}\text { Observed } \\
\text { value }\end{array}$} & \multirow[t]{2}{*}{ Residual* } & \multirow[t]{2}{*}{$\%$ Error $^{* *}$} \\
\hline & $x_{1}$ & $X_{2}$ & & & & & \\
\hline \multirow[t]{2}{*}{$C_{1}$} & \multirow[t]{2}{*}{-0.75} & \multirow[t]{2}{*}{1} & $\mathrm{Y}_{1}(\mathrm{~nm})$ & 93.60 & 95 & 1.4 & 1.5 \\
\hline & & & $\mathrm{Y}_{2}(\%)$ & 75.00 & 74.50 & -2.5 & -3.33 \\
\hline \multirow[t]{2}{*}{$\mathrm{C}_{2}$} & \multirow[t]{2}{*}{-0.92} & \multirow[t]{2}{*}{1} & $\mathrm{Y}_{1}(\mathrm{~nm})$ & 115.4 & 118 & 2.6 & 2.23 \\
\hline & & & $Y_{2}(\%)$ & 78.35 & 77 & -1.35 & -1.72 \\
\hline
\end{tabular}

$*$ residual $=$ actual $($ experimental $)$ value - predicted value. ${ }^{* *}$ error $=[$ predicted value - experimental value/predicted value $] \times 100$

\section{Table 5: Experimental Design with Corresponding Preparations and Results.}

\begin{tabular}{|c|c|c|c|c|c|c|c|c|}
\hline \multirow[t]{2}{*}{ RUN } & \multicolumn{2}{|c|}{$\begin{array}{l}\text { Coded } \\
\text { Values* }\end{array}$} & \multicolumn{2}{|c|}{$\begin{array}{c}\text { Actual } \\
\text { Values }(\mathrm{mg})\end{array}$} & \multirow[t]{2}{*}{$\begin{array}{c}Y_{1} \\
\text { P.S (nm) }\end{array}$} & \multirow[t]{2}{*}{$\begin{array}{c}Y_{2} \\
\text { E.E (\%) }\end{array}$} & \multirow[t]{2}{*}{ PDI } & \multirow[t]{2}{*}{$\begin{array}{c}\text { Drug Release at } \\
8 \mathrm{~h}(\%)\end{array}$} \\
\hline & $x_{1}$ & $x_{2}$ & $x_{1}$ & $X_{2}$ & & & & \\
\hline A1 & -1 & -1 & 5 & 10 & $296 \pm 4$ & $89 \pm 0.5$ & 0.25 & $71 \pm 1.20$ \\
\hline $\mathrm{A} 2$ & 0 & -1 & 10 & 10 & $84 \pm 5$ & $70 \pm 2.00$ & 0.27 & $68 \pm 0.70$ \\
\hline A3 & +1 & -1 & 15 & 10 & $132 \pm 3$ & $62 \pm 0.5$ & 0.24 & $64 \pm 1.0$ \\
\hline A4 & -1 & 0 & 5 & 15 & $254 \pm 5$ & $82 \pm 0.5$ & 0.31 & $73 \pm 0.20$ \\
\hline A5 & 0 & 0 & 10 & 15 & $92 \pm 4$ & $65 \pm 0.5$ & 0.30 & $62 \pm 0.90$ \\
\hline A6 & +1 & 0 & 15 & 15 & $197 \pm 3$ & $58 \pm 1.00$ & 0.24 & $63 \pm 2.0$ \\
\hline A7 & -1 & +1 & 5 & 20 & $109 \pm 4$ & $80 \pm 0.5$ & 0.25 & $72 \pm 0.40$ \\
\hline A8 & 0 & +1 & 10 & 20 & $99 \pm 5$ & $64 \pm 0.5$ & 0.31 & $58 \pm 0.70$ \\
\hline A9 & +1 & +1 & 15 & 20 & $232 \pm 7$ & $53 \pm 4.5$ & 0.26 & $55 \pm 0.90$ \\
\hline
\end{tabular}

(Coded values $*-1=$ low, $0=$ medium and $+1=$ high concentration)

\begin{tabular}{|c|c|c|c|c|c|c|}
\hline Source & $\begin{array}{l}\text { Sum of } \\
\text { Squares }\end{array}$ & Df & $\begin{array}{l}\text { Mean } \\
\text { Square }\end{array}$ & F Value & $\begin{array}{l}\text { p-value } \\
\text { Prob }>\text { F }\end{array}$ & \\
\hline Model & 48993.36 & 5 & 9798.67 & 14.26 & 0.0266 & \multirow{8}{*}{ Significant } \\
\hline$A-X_{1}$ & 1600.67 & 1 & 1600.67 & 2.33 & 0.2244 & \\
\hline $\mathrm{B}-\mathrm{X}_{2}$ & 864.00 & 1 & 864.00 & 1.26 & 0.3438 & \\
\hline$A B$ & 20592.25 & 1 & 20592.25 & 29.97 & 0.0120 & \\
\hline$A^{2}$ & 24938.89 & 1 & 24938.89 & 36.29 & 0.0092 & \\
\hline$B^{2}$ & 997.56 & 1 & 997.56 & 1.45 & 0.3146 & \\
\hline Residual & 2061.53 & 3 & 687.18 & & & \\
\hline Cor Total & 51054.89 & 8 & & & & \\
\hline
\end{tabular}

The Model F-value of 14.26 implies the model is significant. There is only a $2.66 \%$ chance that a "Model F-Value" this large could

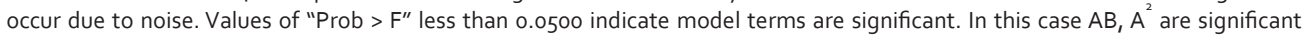
model terms.

for the prepared ASP-niosomes. Maximum entrapment efficiency observed for ASP-niosome A2 containing 10 $\mathrm{mg}$ of cholesterol and $10 \mathrm{mg}$ of Span 60.

By conducting statistical analysis the quadratic model was model was found to be best fit model and polynomial equation is shown below

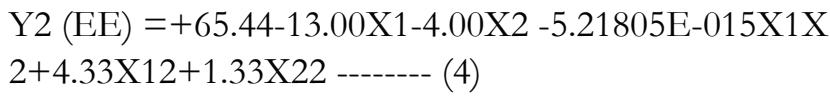
$\mathrm{Y} 2(\mathrm{EE})=+65.44-13.00 \mathrm{X} 1-4.00 \mathrm{X} 2-5.21805 \mathrm{E}-015 \mathrm{X} 1 \mathrm{X}$ $2+4.33 \mathrm{X} 12+1.33 \mathrm{X} 22$

The results of multiple linear regression analysis showed that both the coefficients $\beta 1$ and $\beta 2$ bear a negative sign. Therefore, increasing the concentration of either Cholesterol or Span 60 is expected to decrease the entrapment efficiency. Three-dimensional response surface plot and Two-dimensional contour plot were shown in Figure 8 and Figure 9, indicate the effect of cholesterol and span 60 on the entrapment efficiency 


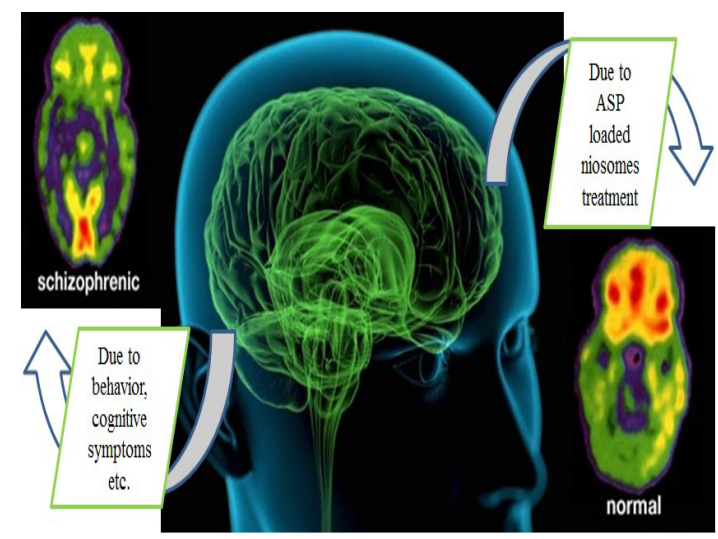

Figure 1: Effect of ASP loaded niosomeson Schizophrenic brain disorder.

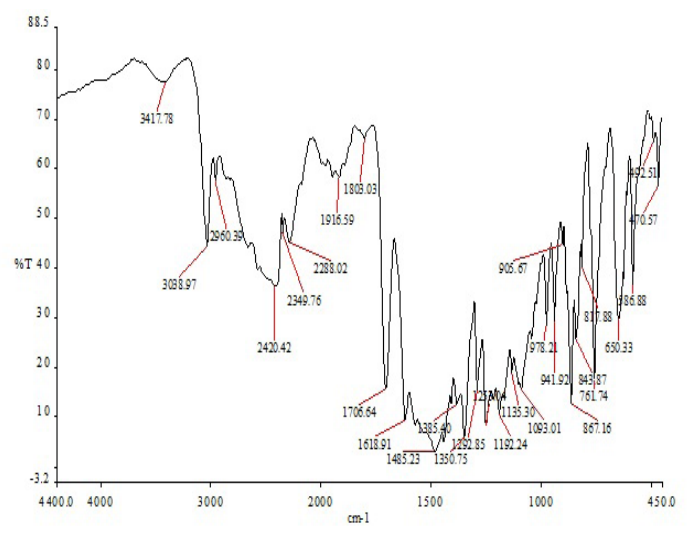

Figure 2: FT-IR spectra of ASP.

of ASP-niosomes. With increasing in the concentration of cholesterol and span 60 were found to influence or decrease the entrapment efficiency of the prepared ASP-niosomes. Graphical representation of entrapment efficiency and particle size is given in Figure 10.

\section{In-vitro drug release}

The in vitro drug release of prepared ASP-niosomes A1A9 ranges from $55 \pm 0.90$ to $73 \pm 0.20 \%$ and the values are presented in Table 5. The release profile of the ASP from the niosomes in PBS $\mathrm{pH} 7.4$ was shown in Figure 11. All ASP-niosomes showed burst release due to dissolution of surface of ASP from niosomes initially followed by sustained release. The optimized ASPniosome A2 was showed better cumulative percentage drug release $68 \pm 1.20 \%$ at the end of $8 \mathrm{~h}$ as compare to the other ASP-niosomes. From the interpretation given in Table 8, the best fitted kinetic model was found to be Korsmeyer-Peppas model (Figure 12).

\section{Surface morphology}

The surface morphology of optimized ASP-niosome A2 was spherical shape and crystalline structure as shown in Figure 13.

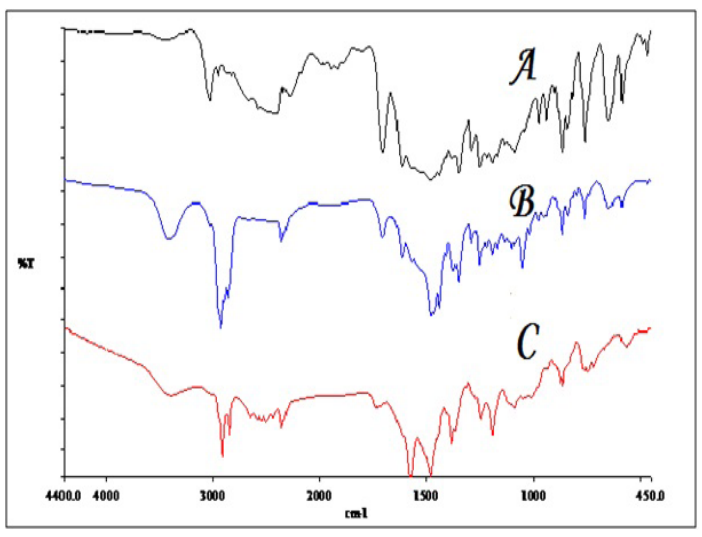

Figure 3: FTIR spectra of ASP (A), ASP + Cholesterol (B), ASP + Span 60 (C).

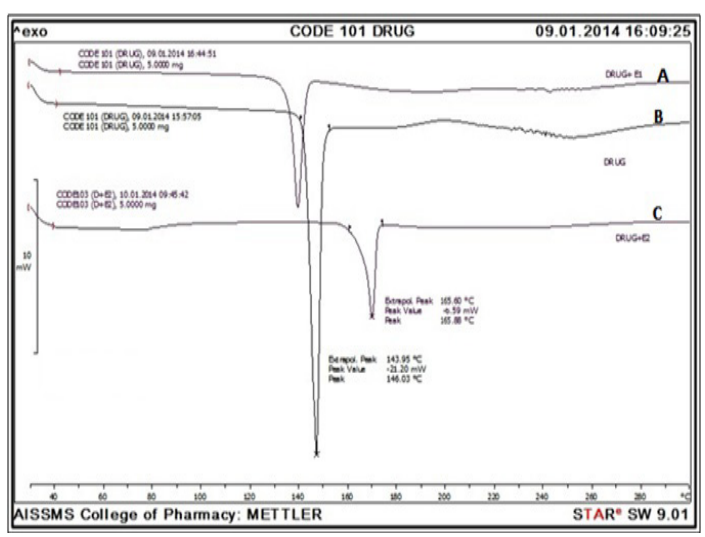

Figure 4: DSC Thermograms of ASP + Cholesterol (A), ASP (B), ASP + Span 60(C).

\section{Zeta potential}

The surface charge property and particle stability of optimized ASP-niosome A2 was potential of physical stability as it has zeta potential of $-17.53 \mathrm{mV}$ as shown in Figure 14.

\section{Validation of optimized preparations/check point analysis}

The experimentally observed values of the responses were compared with that of the predicted values and the prediction error for the two responses were found varying between 3.33 and $2.25 \%$ (Table 4).

\section{In-vivo Studies}

\section{Pharmacodynamics study}

The antipsychotic effect of optimized ASP-niosome A2 was carried out by pharmacodynamic study. The locomotor activity and behavioral response of rats were assessed by injecting of ketamine $(30 \mathrm{mg} / \mathrm{kg}$ ) i.p. daily for five consecutive days. This dose was found to be increased glutamate outflow in the prefrontal cortex and also sub anesthetic dose of ketamine shows psychtomimetic effects with characteristic behavioral 


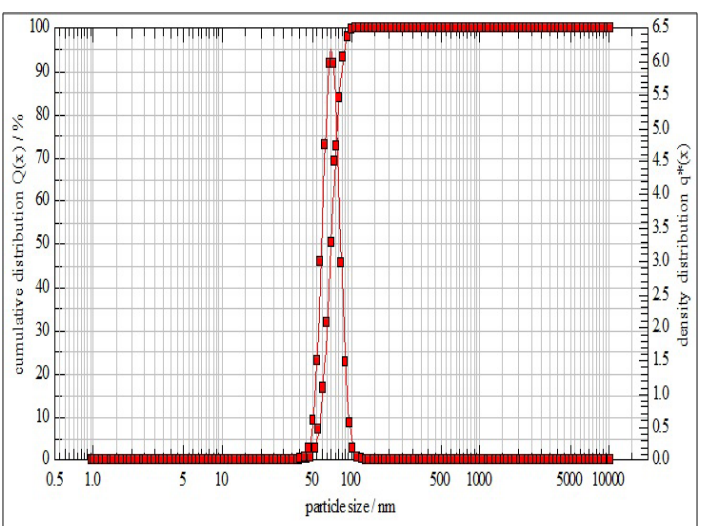

Figure 5: Particle size and Size distribution of ASP-Niosomes.

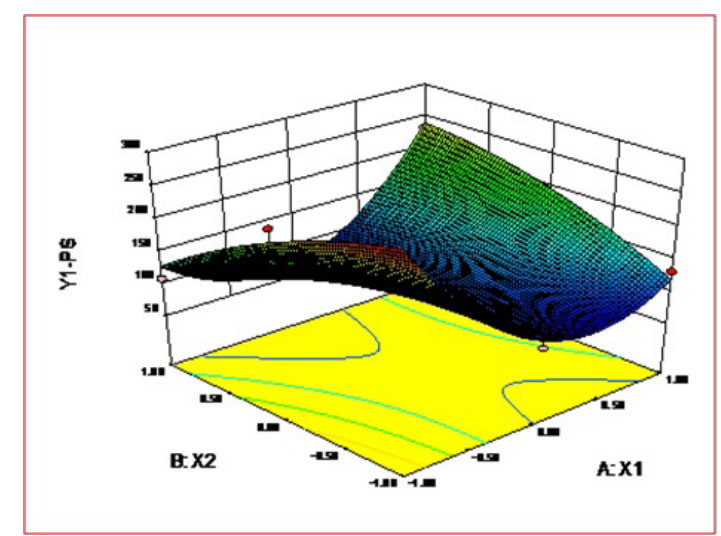

Figure 6: Response surface plot illustrating the influence of Cholesterol and Span 60 on the particle size.

response such as staggered locomotion and increased [14C] 2-DG uptake in the limbic cortical regions, hippocampus, thalamic nuclei and baso lateral nucleus of the amygdale. Psychosis was induced in rats after Ketamine injection. The psychosis was induced and confirmed by the depressant activity, behavioral response like drowsiness and decreased locomotor activity. The psychosis induced rats were then treated p.o. $(0.3 \mathrm{mg} / \mathrm{kg})$ of ASP-niosome A2 and API solution. The locomotor activity was checked for 5 minutes in open field arena chamber at different time intervals. The locomotion's were found significantly improved with time as shown in Table 9 for ASP-niosome A2 and also, behavioral response became as similar as control (Figure 15).

\section{Pharmacokinetic study}

The optimized preparation A2 was analyzed in the plasma samples at different time intervals by HPLC (Figure 16) and it was found $4.412 \mathrm{~min}$. The ASP-niosome A2 was detected into the plasma and AUC of ASP- niosome is as shown in Figure 17. The peak plasma concentration of ASP-noisome A2was found increased from 4-11 ng/

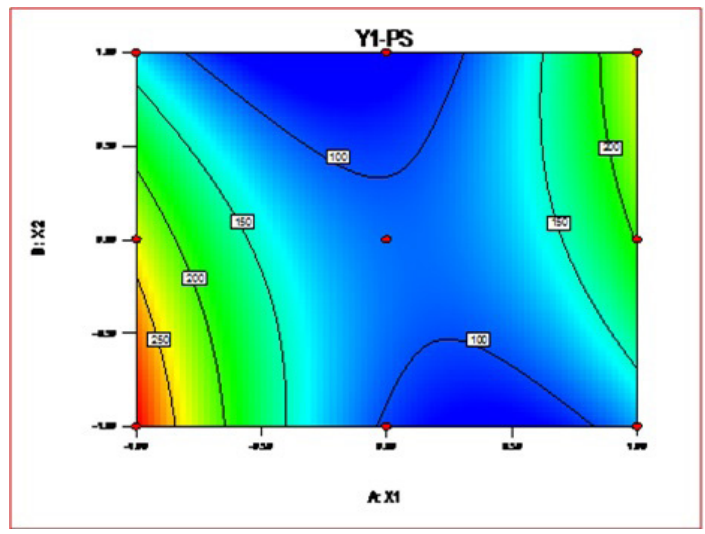

Figure 7: Contour plot illustrating the influence of Cholesterol and Span 60 on the particle size of niosomes.

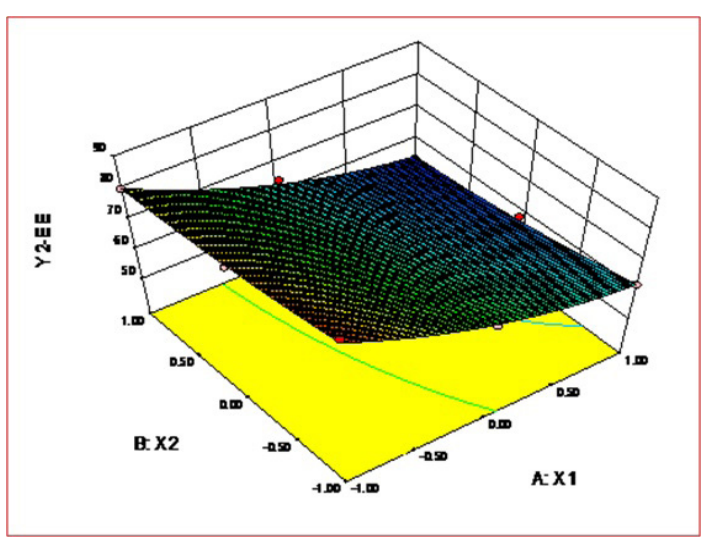

Figure 8: Response surface plot illustrating the influence of Cholesterol and Span 60 on the entrapment efficiency.

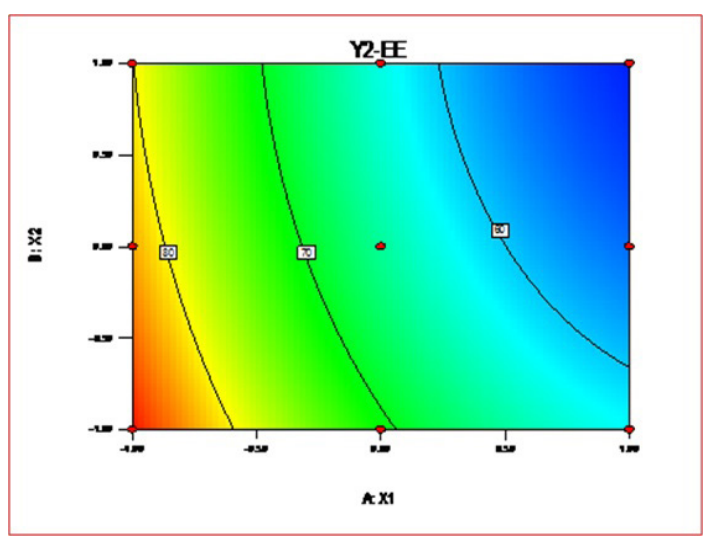

Figure 9: Contour plot illustrating the influence of Cholesterol and Span 60 on the entrapment efficiency.

$\mathrm{mL}$ by orally administration, having $35 \%$ bioavailability. The peak plasma concentration obtained of optimized niosome of Asenapine maleate A2 and ASP was 16.12 $\mathrm{ng} / \mathrm{mL}$ and $4.62 \mathrm{ng} / \mathrm{mL}$, respectively. The half-life $\mathrm{t} 1 / 2$ of the optimized ASP-niosome A2 and ASP was found $37.18 \mathrm{~h}$ and $5.21 \mathrm{hr}$, respectively. This observation was suggested that the formulation of niosomes of ASP is possible which would reduce the frequency of administration of ASP and help to increase patient 


\begin{tabular}{|c|c|c|c|c|c|c|}
\hline Source & $\begin{array}{l}\text { Sum of } \\
\text { Squares }\end{array}$ & Df & $\begin{array}{l}\text { Mean } \\
\text { Square }\end{array}$ & F Value & $\begin{array}{l}p \text {-value } \\
\text { Prob }>\text { F }\end{array}$ & \\
\hline Model & 1151.11 & 5 & 230.22 & 107.17 & 0.0014 & \multirow{7}{*}{ Significant } \\
\hline A- $X_{1}$ & 1014.00 & 1 & 1014.00 & 472.03 & 0.0002 & \\
\hline $\mathrm{B}-\mathrm{X}_{2}$ & 96.00 & 1 & 96.00 & 44.69 & 0.0068 & \\
\hline$A B$ & $\begin{array}{c}2.274 \mathrm{E}- \\
013\end{array}$ & 1 & $\begin{array}{c}2.274 \mathrm{E}- \\
013\end{array}$ & $\begin{array}{c}1.058 \mathrm{E}- \\
013\end{array}$ & 1.0000 & \\
\hline$A^{2}$ & 37.56 & 1 & 37.56 & 17.68 & 0.0249 & \\
\hline$B^{2}$ & 3.56 & 1 & 3.56 & 1.66 & 0.2885 & \\
\hline Residual & 6.44 & 3 & 2.15 & & & \\
\hline Cor Total & 1157.56 & 8 & & & & \\
\hline
\end{tabular}

The Model F-value of 107.17 implies the model is significant. There is only a $0.14 \%$ chance that a "Model F-Value" this

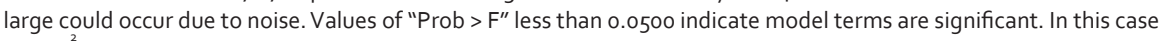
$A, B, A^{2}$ are significant model terms.

\section{Table 8: Various Model Fittings for Optimized ASP-Niosome A2.}

\begin{tabular}{|c|c|c|c|}
\hline Sr. No. & Model & Correlation Coefficient $\left.\mathbf{( R}^{\mathbf{2}}\right)$ & $\mathbf{K}$ \\
\hline 1 & Zero Order & 0.9580 & 0.4109 \\
\hline 2 & First Order & 0.9598 & -0.0042 \\
\hline 3 & Matrix & 0.9860 & 0.9841 \\
\hline 4 & Korsmeyer Peppas & $0.9942(n=0.6867)$ & 0.7229 \\
\hline 5 & Hixson Crowell & 0.9592 & -0.0014 \\
\hline
\end{tabular}

\section{Table 9: Effect of Optimized ASP-Niosome A2 on} Locomotor Activity.

\begin{tabular}{|c|c|}
\hline Group & Locomotor counts \\
\hline Control & $188.8 \pm 5.94$ \\
\hline Disease Control & $28 \pm 1.31 \mathrm{C}$ \\
\hline API Application & $53 \pm 3.67 \#$ \\
\hline Formulation & $176.5 \pm 3.25 @$ \\
\hline
\end{tabular}

Actual value represents mean \pm S.E.M. $n=6$.

${ }^{c} P<0.001$ compared with control rats (ketamine)

${ }^{\#} P<0.01$ compared with API application rats

${ }^{\circledR} p<0.001$ compared with formulation application rats

(one way ANOVA followed by Tukey test)

\section{Table 10: Pharmacokinetic Data of ASP-Niosomes.}

\begin{tabular}{|c|c|c|c|}
\hline Paramater & Unit & $\begin{array}{c}\text { Value of ASP- } \\
\text { Niosome } \text { A }_{2}\end{array}$ & $\begin{array}{c}\text { Value of ASP } \\
\text { (API) }\end{array}$ \\
\hline $\mathrm{C}_{\max }$ & $\mathrm{ng} / \mathrm{mL}$ & 16.12 & 4.62 \\
\hline $\mathrm{T}_{\max }$ & $\mathrm{Hr}$ & 2 & 1 \\
\hline $\mathrm{AUC}_{0-\mathrm{t}}$ & $\mathrm{ng} / \mathrm{mL}^{*} \mathrm{~h}$ & 49.38 & 14.22 \\
\hline $\mathrm{t}_{1 / 2}$ & $\mathrm{Hr}$ & 37.18 & 5.21 \\
\hline
\end{tabular}

PS and EE\% of ASP- Niosomes

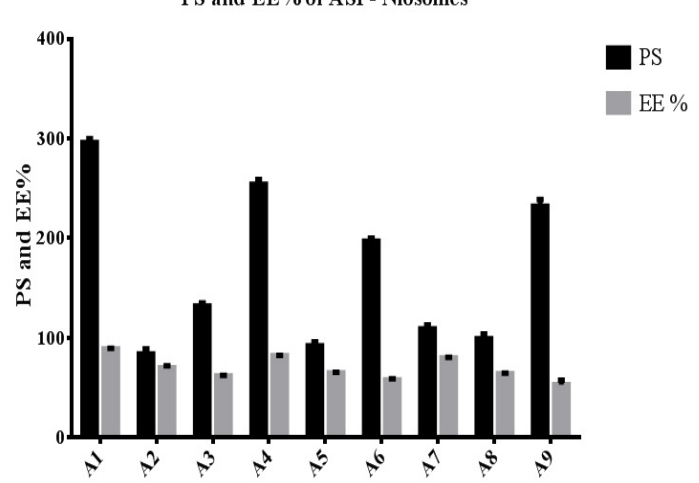

Figure 10: Graphical representation of Entrapment efficiency and particle size of formulations.

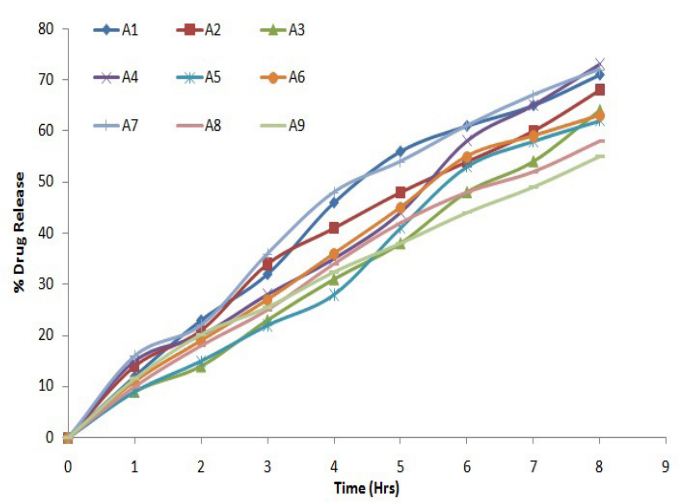

Figure 11: In vitro drug release profile of ASP-Niosome preparation. 


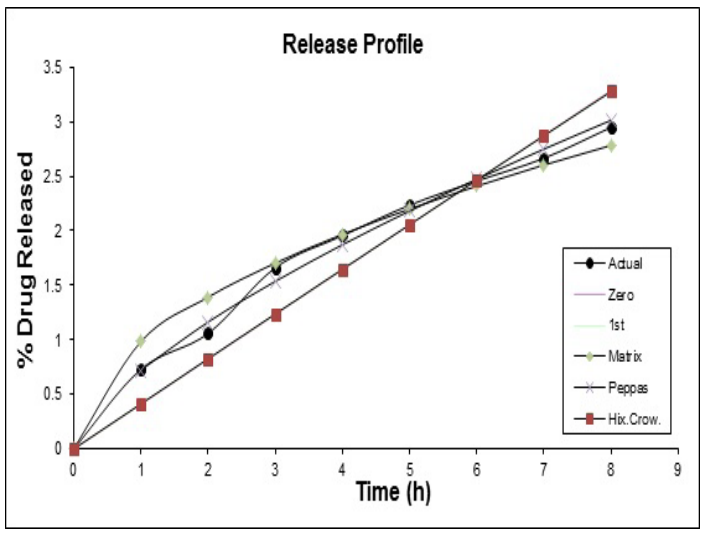

Figure 12: Best fitted dissolution model for optimized optimized ASP -Niosome A2.
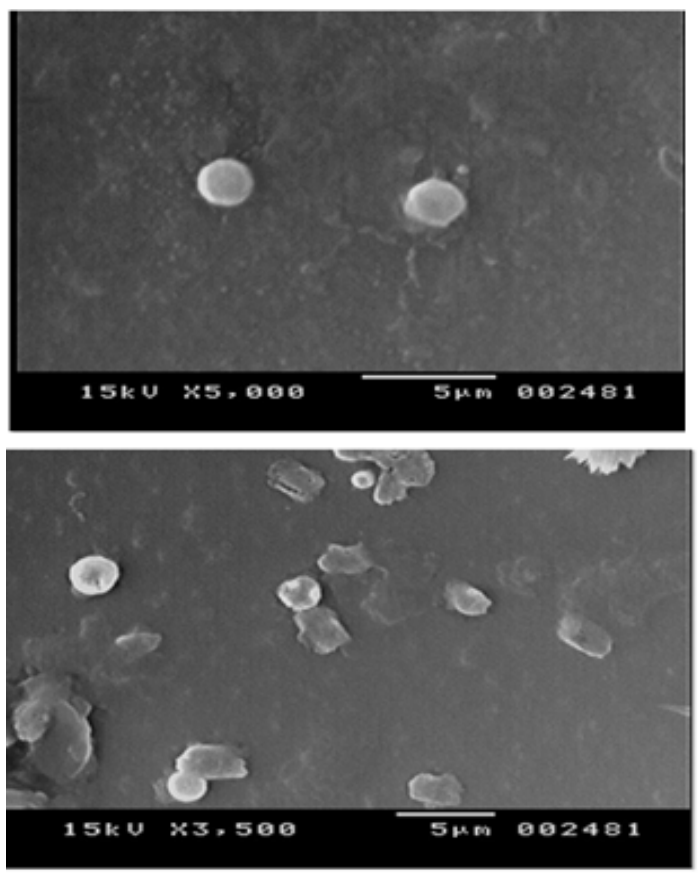

Figure 13: Morphology of optimized ASP -Niosome A2 by SEM Analysis.

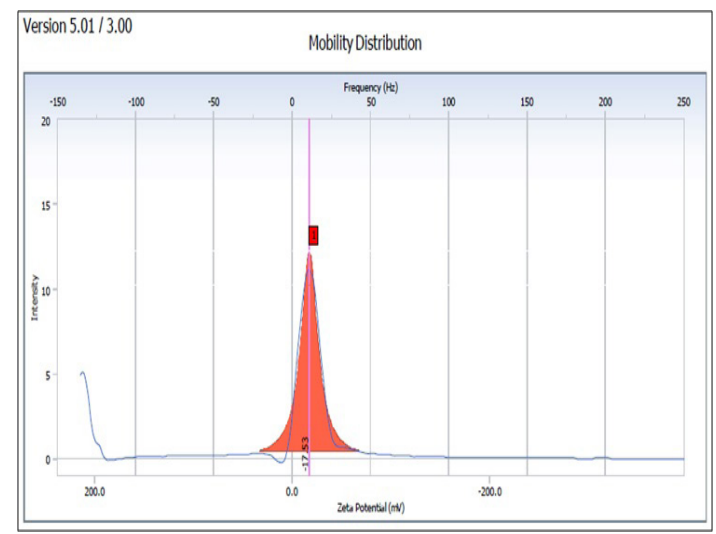

Figure 14: Zeta potential (ל) determination of optimized optimized ASP-Niosome A2.

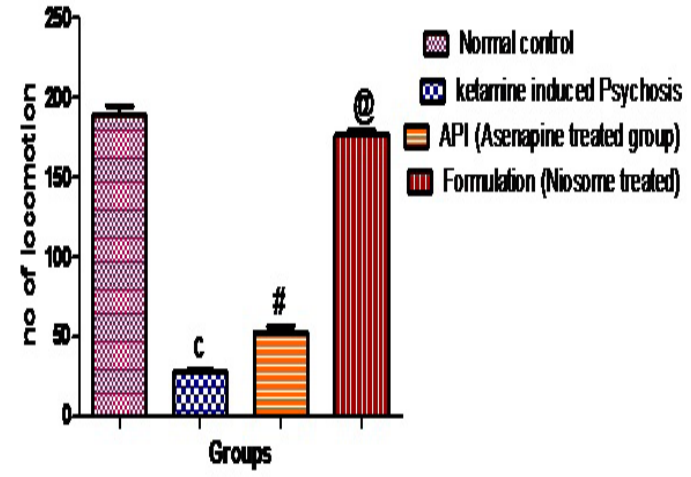

Figure 15: Study of effect of optimized ASP -Niosome A2 on behavioural activity on Rats.

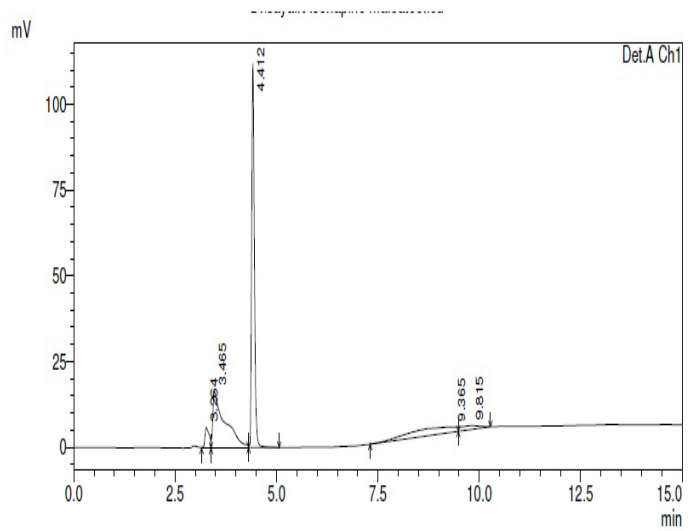

Figure 16: Typical chromatogram of ASP -Niosome A2 (100 $\mu \mathrm{g} / \mathrm{mL}$ ) using RP HPLC.

Phram cokinetic study of ASP- Niosome A2

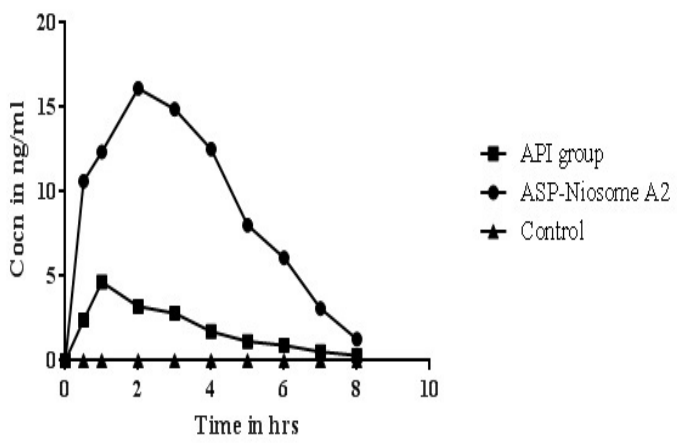

Figure 17: AUC of optimized ASP -Niosome A2.

compliance in the treatment of psychotic disorders like schizophrenia and bipolar disorder I. Pharmacokinetic parameters are shown in Table 10.

\section{CONCLUSION}

Based on the above study we have concluded that selection of a suitable composition of cholesterol and span 60 . The desired entrapment efficiency and particle size were achieved by using a $3^{2}$ factorial design. The 
optimized ASP-niosome A2 showed better in vitro drug releaseas compare to the other ASP-niosomes and also best fitted kinetic model was found Korsmeyer-Peppas (K-P) model and the the drug release is controlled by diffusion process. The surface morphology of ASPniosome A2 by using scanning electron microscopy reveals that niosomes were spherical in shape and the zeta potential value showed that niosomes have sufficient charge and mobility to inhibit aggregation and are stable in suspension as surface charge prevents aggregation of the particles. The PK-PD studies concluded that ASPniosome A2 shows greater pharmacokinetic values than reported value of pure ASP. In pharmacodynamic study, locomotor activity and behavioral response was found gradually improved with ASP-niosome A2 showing its improved antipsychotic activity. From the present investigation, it may be concluded that niosomes may increase the oral bioavailability of Asenapine maleate.

\section{ACKNOWLEDGEMENT}

The authors are grateful to Lupin Research Park., Pune Mr. Kiran Bankar for providing gift sample of drug and Sinhgad College of Pharmacy, Vadgaon (Bk), Pune, India for providing facilities.

\section{CONFLICT OF INTEREST}

The authors declare no conflicts of interest.

\section{ABBREVATIONS}

$\%$ : Percent; $\lambda_{\text {max: }}$ Wavelength of maximum absorbance; ${ }^{\circ} \mathrm{C}$ : Degree celcious; $\mathbf{C m}$ : centimeter; $\mu \mathrm{g}$ : Micro gram; hr: Hour; LOD: Limit of detection; LOQ: limit of quantification; Mg: Milligram; Min: Minute; $\mathrm{mL}$ : Milliliter; $\mu \mathrm{L}$ : Microliter; $\mathbf{r}^{2}$ : Regression coefficient; RP-HPLC: Reverse phase-high performance liquid Chromatography; Rpm: Revolutions per minute; SD: Standard deviation; $\mathbf{t}_{\mathbf{R}:}$ Retention time; $\mathbf{U V}$ : Ultra Violet.

\section{REFERENCES}

1. Siris SG. Suicide and schizophrenia. J Psychopharmacol. 2001;15(2):127-35.

2. Lambert T. Selecting patients for long-acting novel antipsychotic therapy. Australas Psychiatry. 2006;14(1):38-42.

3. Conley RR, Kelly DL. Management of treatment resistance in schizophrenia. Biol Psychiatry. 2001;50(1):898-911.

4. Avachat AA, Kapure SS. Asenapine maleate in situ forming biodegradable implant: An approach to enhance bioavailability. Int J Pharm. 2014;477(12):64-72. doi: http://dx.doi.org/10.1016/j.ijpharm.2014.10.006

5. Makeshwar K, Wasankar S. Niosomes: A novel drug delivery system. Asia J Pharma Research. 2013;3(1):16-20.

6. Bartelds R, Nematollahi MH, Pols T, Stuart MCA, Pardakhty A, Asadikaram G. Niosomes, an alternative for liposomal delivery. PLoS One. 2018;13(4):e0194179

7. United States Food and Drug Administration, Press release. FDA Approves Saphris to Treat Schizophrenia and Bipolar Disorder. 2007. Available in: http://
www.fda.gov/News Events/News room/Press Announcements/ucm177401. htmL

8. Schering-Plough Corporation, Saphris (Asenapine) Sublingual Tablets US Prescribing Information. 519-520. Available in: http://www.spfiles.com/ pisaphrisv1.pdf

9. Vieta E. Asenapine: A new focus on the treatment of mania. Rev Psiquiatr Salud Ment. 2011;4(2):101-8.

10. Wiley $\mathrm{VCH}$, Verlag GH, KGa A. Process Understanding: For Scale-up and Manufacture of Active Ingredients. Ian Houson. 2011;1:23-8.

11. Miksinski S. Regulatory Assessment of Applications Containing QbD Elements-Reviewer Experience. Am Ass Pharm Sci. 2012;1-34.

12. ICH: Q8 (R1). Pharmaceutical Development. Geneva, Switzerland. 2008.

13. Tan Q, Liu S, Chen X, et al. Design and Evaluation of a Novel EvodiaminePhospholipid Complex for Improved Oral Bioavailability. AAPS Pharm Sci Tech. 2012;13(2):534-47. doi: 10.1208/s12249-012-9772-9

14. Cui F, Shi K, Zhang L, Tao A, Kawashima Y. Biodegradable Nanoparticles loaded with Insulin-Phospholipid Complex for Oral Delivery: Preparation, in vitro characterization and in vivo Evaluation. J Contr Rel. 2006;114(2):242-50. doi:10.1016/j.jconrel.2006.05.013

15. Avachat AA, Parpani SS. Formulation and development of bi-continuous nanostructured liquid crystalline particles of efavirenz. Colloids and Surface B: Biointerfaces. 2015;126(1):87-97. doi:10.1016/j.colsurfb.2014.12.014

16. Zhang J, Tang Q, Xu X, Li N. Development and Evaluation of a Novel Phytosome-loaded Chitosan Microsphere System for Curcumin Delivery. Int J Pharm. 2013;448(1):168-74. doi:10.1016/j.jpharm.2013.03.021

17. Keservani R, Sharma A, Ayaz M. Novel Drug Delivery System for the Vesicular Delivery of Drug by the Niosomes. Int J Research Contr Release. 2011;1(1):1-8.

18. Chandu VP. Niosomes: A Novel Drug Delivery System. Int J Nov Trends Pharma Sci. 2012;2(1):25-31.

19. Madhav NVS, Saini A. Niosomes: A Novel drug delivery system. Int J Research Pharm Chem. 2011;1(3):498-511.

20. Andreson MJ, Whitcomb PJ. DOE Simplified: Practical Tools for Effective Experimentation, $2^{\text {nd }} e d$.., Taylor and Francis group, Boca Raton, New York. 2007;3:1-3.30.

21. Dumbare A, Shelke P, Gadhave M. Optimization: A Review. Int J Uni Pharm Life Sciences. 2012;2:2249-6793.

22. Mandlik S, Nandare D, Joshi M. Statistical optimization of or dispersible tablets containing Telmisartan using factorial design and response surface methodology. Res J Pharm Tech. 2009;2(3):548-51.

23. EIGamal SS, Naggar VF, Allam AN. Optimization of acyclovir oral tablets based on gastro retention technology: Factorial design analysis and physicochemical characterization studies. Drug Dev Indus Pharmacy. 2011;37(7):855-67.

24. Umah RS, Vignesh M. Formulation and evaluation of noisome containing Olanzapine. International Journal of Health and Pharmaceutical Sciences. 2011;1(3):100-12.

25. Guinedi A, Mortada N, Mansour S. Preparation and evaluation of reverse phase evaporation and multi lamellar niosomes as ophthalmic carriers of acetazolamide. Int J Pharm. 2005;306(1-2):71-82.

26. Rani S, Hari V. Niosomal Formulation of Orlistat: Formulation and in-vitro evaluation. Int J of Drug Dev Res. 2012;3(3):300-11.

27. Marston HM, Young JW, Geyer MA. Asenapine effects in animal models of psychosis and cognitive function. Psych Pharma. 2009;206(4):699-714.

28. Becker A. Ketamine-induced changes in rat behaviour: A possible animal model of schizophrenia. Progress in Neuro-Psychopharmacology and Biological Psychiatry. 2003;27(4):687-700.

29. Moghaddam B, Adams B, Verma A. Activation of glutamatergic neurotransmission by ketamine: A novel step in the pathway from NMDA receptor blockade to dopaminergic and cognitive disruptions associated with the prefrontal cortex. J Neurosci. 1997;17(8):2921-7.

30. Duncan G, Moy S. Metabolic mapping of the rat brain after sub anesthetic doses of ketamine: Potential relevance to schizophrenia. Brain Res. 1998;787(2):181-90.

31. Duncan G, Leipzig J, Mailman R. Differential Effects of Clozapine and Haloperidol on Ketamine-Induced Brain Metabolic Activation. Brain Res. 1998;812(1-2):65-75. 
PICTORIAL ABSTRACT

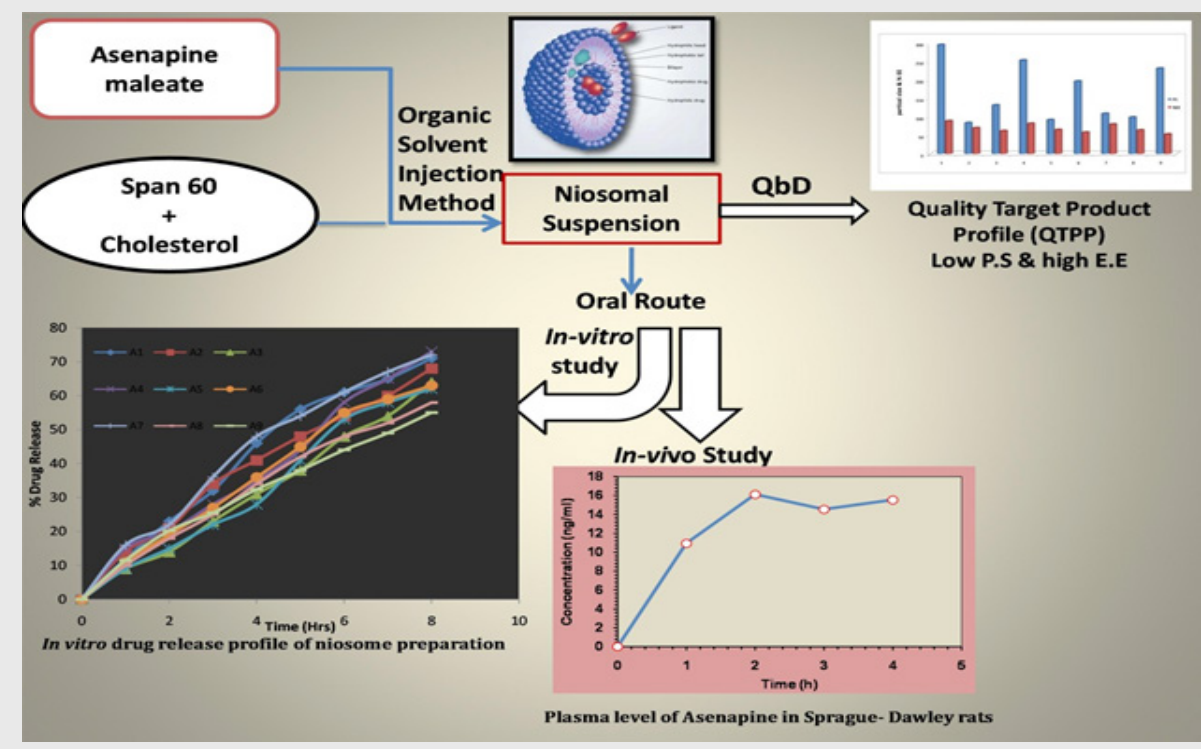

Cite this article: Singh RP, Narke RM, Jadhav PV. Formulation and Evaluation of Asenapine Maleate Loaded Niosomes for the Treatment of Schizophrenia. Indian J of Pharmaceutical Education and Research. 2020;54(2s):s128-s139. 